\title{
No association between the use of Bti for mosquito control and the dynamics of non-target aquatic invertebrates in French coastal and continental wetlands
}

\author{
Laurent Lagadic a, $*$, Ralf B. Schäfer b, Marc Roucaute a, Eduard Szöcs b, Sébastien Chouin c, Jérôme de Maupeou c, \\ Claire Duchet d, Evelyne Franquet e, Benoit Le Hunsec c, Céline Bertrand e, Stéphanie Fayolle e, Benoît Francés d, \\ Yves Rozier f, Rémi Foussadier f, Jean-Baptiste Santoni g, Christophe Lagneau d

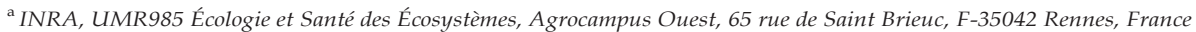 \\ ${ }^{\mathrm{b}}$ Quantitative Landscape Ecology, Institute for Environmental Sciences, University of Koblenz-Landau, Fortstraße 7, D-76829 Landau, Germany \\ ${ }^{c}$ Etablissement Interdépartemental pour la Démoustication du Littoral Atlantique, 1 rue Toufaire, F-17300 Rochefort-sur-Mer, France \\ d Entente Interdépartementale pour la Démoustication du Littoral Méditerranéen, 165 avenue Paul-Rimbaud, F-34184 Montpellier, France

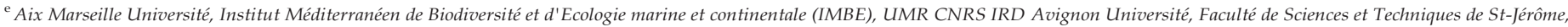 \\ F-13397 Marseille, France \\ ${ }^{\mathrm{f}}$ Entente Interdépartementale Rhône-Alpes pour la Démoustication, 31 Chemin des Prés de la Tour, F-73310 Chindrieux, France \\ ${ }^{\mathrm{g}}$ Conseil Départemental de Corse du Sud, Service de Lutte Antivectorielle, Hôtel du Département, Palais Lantivy, BP 414, F-20183 Ajaccio, France
}

\section{H I G H L IG H T S}

- Bti is used in a variety of continental and coastal wetlands against mosquito larvae.

- Bti dosages recommended for mosquito control do not affect non-target invertebrates.

- The abundance of most-at-risk chironomids varies independently from $B t i$ treatments.

- No immediate or long-term effects were shown on invertebrate diversity and abundance.

- Invertebrate community dynamics is mainly driven by flooding frequency and duration.

\section{GR A P H I C A L A B S T R A C T}

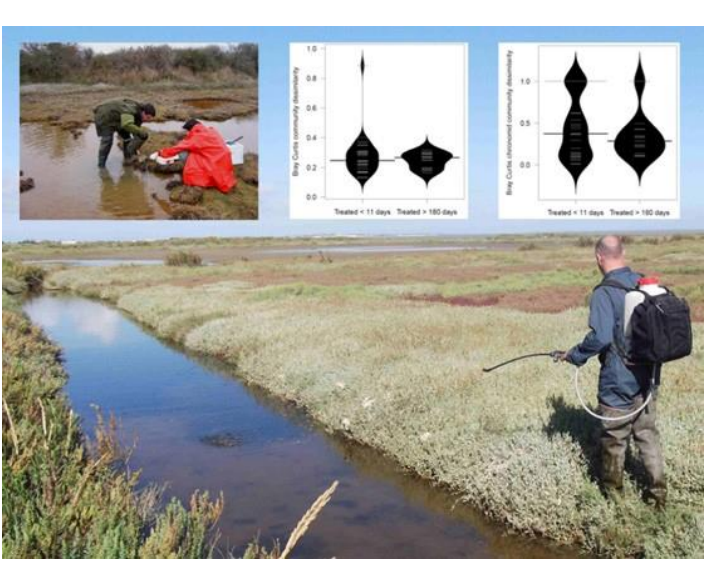

a bstract

The environmental safety of Bacillus thuringiensis subsp. israelensis (Bti) is still controversial, mainly because most of the previous field studies on its undesired effects were spatially limited and did not address the relationship between community similarity and application time and frequency. No general statement can therefore be drawn on the usage conditions of Bti that insure protection of non-target organisms.

The present study was conducted in eight sites distributed over the main geographical sectors where mosquito control is implemented in mainland France and Corsica. Changes in non-target aquatic invertebrates were followed at elapsed time after repeated applications of two Bti formulations (VectoBac® WDG or 12AS) up to

\footnotetext{
* Corresponding author at: INRA, UMR985 Écologie et Santé des Écosystèmes, Agrocampus Ouest, 65 rue de Saint Brieuc, CS 84215 , F-35042 Rennes, France.

E-mail address: Laurent.Lagadic@rennes.inra.fr (L. Lagadic).
} 
Keywords:

Bacillus thuringiensis israelensis Biopesticide

Mosquito control

Aquatic non-target invertebrates

Chironomids

Field biomonitoring four consecutive years. We examined the influence of both larvicide treatments and environmental variables on community dynamics and dissimilarity between treated and control areas. As it can be argued that chironomids are the most vulnerable group of non-target invertebrates, we scrutinised potential Bti-related effects on the dynamics of their community.

The use of VectoBac ${ }^{\circledR}$ WDG and 12AS in coastal and continental wetlands had no immediate or long-term detectable effect on the taxonomic structure and taxa abundance of non-target aquatic invertebrate communities, including chironomids. This applied to the main habitats where mosquito larvae occur, regardless of their geographic location. Flooding, whose frequency and duration depend on local meteorological and hydrological conditions, was identified as the main environmental driver of invertebrate community dynamics.

Our findings add support to the environmental safety of currently available Btiformulations when following recommended application rates and best mosquito control practices.

\section{Introduction}

Since the late 70's, Bacillus thuringiensis subsp. israelensis (Bti) is used worldwide to control larval populations of mosquitoes, chironomids and blackflies. Over the past decade, the use of this biopesticide has greatly increased, not only because it is an alternative to synthetic insecticides (Crickmore, 2005), which are less specific and currently undergo severe usage restrictions, but also because of the rapid expansion of mosquito-borne diseases associated with climate change (Reiter, 2010; Medlock and Leach, 2015). Several Bti formulations have therefore been developed, as liquid, water-dispersible granules or corncob granules (e.g., VectoBac ${ }^{\circledR} 12 \mathrm{AS}$, WDG and G, respectively), for uses in various habitat conditions. Irrespective of the formulation, the main advantage of $B t i$ is related to the specific mode of action of its toxins, which makes it highly selective for Culicidae (Bravo et al., 2011; Després et al., 2011). Indeed, with respect to non-target species, the vast majority of field studies indicate that the use of Bti in environmentally safe (e.g., Boisvert and Boisvert, 2000; Lacey and Merritt, 2004; Stark, 2005). Nevertheless, in many countries, Public Authorities are still concerned by possible undesirable ecological impacts of this larvicide (US Fish and Wildlife Service, 2011; Land and Miljand, 2014). This has fuelled a permanent debate between regulatory authorities, policyand decision-makers, public operators for mosquito control, and scientists. This debate was recently reignited after a study claimed that $B t i$ was responsible for a decreased breeding success in the house martin Delichon urbicum as an indirect consequence of altered food webs (Poulin et al., 2010). Although this study contrasted with previous results on birds (Hanowski et al., 1997a,b; Niemi et al., 1999; Timmermann and Becker, 2003), it prompted novel investigations into Btisafety. For example, potential endocrine disrupting effects of several $B t i$ formulations, including VectoBac ${ }^{\circledR}$ WDG, and the active ingredient (as VectoBac ${ }^{\circledR}$ Technical Powder) were investigated using molecular assays for detecting estrogenic activity and steroidogenesis alterations (Maletz et al., 2015). No sign of endocrine activity was detected in water sprayed with Bti formulations, which is in agreement with regulatory statements (e.g., US EPA, 1998). At the opposite of these molecularinvestigations, ecosystem-level studies were recently conducted on communities of aquatic microorganisms. Using gene sequencing technologies, Duguma et al. (2015) showed that the biomass, abundance and diversity of microorganisms were affected only by a high dosage of VectoBac ${ }^{\circledR}$ G (approx. twice the maximal application rate recommended for mosquito control) applied in outdoor aquatic microcosms. More importantly, Duguma et al. (2015) demonstrated that the reduced grazing pressure resulting from the reduction of mosquitolarvae populations did not enhance microalgal biomass. This supports the absence of a top-down regulation of microorganism communities by mosquito larvae (Su and Mulla, 1999a; Fayolle et al.,2015).

Beside their ability to detect immediate effects of Bti treatments, long-term field studies are most appropriate to depict indirect effects of the larvicide on non-target organisms. Previous studies mainly focused on aquatic invertebrates because they share the same biotope as mosquito larvae. In addition, some of them (e.g., chironomids) are phylogenetically close to mosquitoes and therefore may have a comparable sensitivity to Bti. Thus, a field study conducted between 1991 and 1993 in Minnesota freshwater wetlands aerially sprayed with VectoBac ${ }^{\circledR} \mathrm{G}$, showed a $60-80 \%$ decrease in chironomid abundance and a reduction in insect genera richness and total biomass (Hershey et al., 1995, 1998; Niemi et al., 1999). However, a follow-up study in 1997-1998 showed that, after intensive and continuous use of VectoBac ${ }^{\circledR}$ G for eight years, the entire macroinvertebrate community remained unaffected, and overall chironomid numbers or biomass were similar, although taxa from the Chironomini tribe were confirmed as the most sensitive to Bti (Balcer et al., 1999). Similarly, no adverse effects of aerial applications of VectoBac ${ }^{\circledR} G$ for six years were found on species richness and production of chironomids, including Chironomini and Orthocladiinae, in temporary wetlands of the River Dalälven floodplain (Lundström et al., 2010a,b; Persson Vinnersten et al., 2010). Instead, VectoBac ${ }^{\circledR}$ treatments were associated with increased chironomid larvae richness (Lundström et al., 2010a), which may be attributed to a release from competition with mosquitoes (Heurteaux, 1999). This is in agreement with a study in Morbihan (South Brittany, France) coastal wetlands where the abundance of the larvae and pupae of chironomids, including Chironomini and Orthocladiinae, was higher in areas sprayed with VectoBac ${ }^{\circledR} 12 \mathrm{AS}$ and WDG (Caquet et al., 2011). Monitoring of the same site for five additional years showed that long-term evolution of the non-target invertebrate community structure in temporary brackish waters was not driven by repeated $B t i$ treatments (Lagadic et al., 2014). Although this fully supports results of the vast majority of previous field studies (e.g., Barnes and Chapman, 1998; Balcer et al., 1999; Russell et al., 2009), ecological effects of contaminants depend on the environmental context (Clements et al., 2015). Results of the studies conducted in mosquito-controlled areas are thus linked to local environmental conditions (e.g., hydrodynamics, vegetation typology) and mosquito control practices, including the type of Bti formulation. The present study was therefore implemented in a wide range of sites distributed across mainland France and Corsica. Both coastal and continental wetlands where two Bti formulations, namely VectoBac ${ }^{\circledR}$ WDG and 12AS, are used to control larval populations of mosquitoes, were included in the survey of non-target aquatic invertebrate communities which was conducted annually up to four years. Because Boisvert and Boisvert (2000) attributed erroneous conclusions and conflicting results of paststudies to discrepanciesinexperimental designs and methods, comparable control and VectoBac ${ }^{\circledR}$ treated areas were selected, where invertebrates were repeatedly sampled. The first tested hypothesis was that the dynamics of invertebrate communities is associated with the time since Bti application. Immediate effects (first two weeks after treatment) might be assigned to direct toxicity whereas long-lasting effects (over several months) encompass both direct and indirect mechanisms, including alteration of trophic relationships. Given their relative sensitivity to Bti (Ali et al., 1981; Yiallouros et al., 1999; Boisvert and Boisvert, 2000; Ali and Lobinske, 2002), chironomids were expected to be at higher risk from the treatments than other invertebrate groups, and part of the analysis was therefore concentrated on them. 


\section{Materials and methods}

\subsection{Study sites}

The study was performed from February 2011 to October 2014 in eight sites located along the Atlantic coast, in the Rhône-Alpes Region, in the Camargue and in South Corsica (Fig. 1 and Table S1 in Appendix A).

The sites were chosen in wetlands regularly flooded by incoming estuary water at high tide or by overflowing of neighbouring rivers for the coastal and continental regions, respectively. In both regions, rainfalls also contributed to flooding. This resulted in varying frequency and duration of flooding among sites (Fig. S1 in Appendix A). All sites were lo-

cated in or next to Natura 2000 areas. The site structure ranged from open waters with no or sparse vegetation to waters heavily vegetated (Table S1). In each site, an untreated, control area was delimited before the survey started. Control areas were either never treated, or left untreated for more than one year before the start of this study, so that any previous larvicide was degraded (Table S1). Close to the control area, a zone of similar surface was delimited, where VectoBac ${ }^{\circledR}$ was ap- plied.

Control and treated areas were separated by a 50-100-m wide buffer zone in order to prevent VectoBac ${ }^{\circledR}$ to reach the control areas as a result of spray drift.

\subsection{Treatments}

VectoBac $($ (ValentBioSciences, Libertyville,IL,USA) was used as the formulations WDG (37.4\% Bti, strain AM 65-52; $\left.3000 \mathrm{ITU} \mathrm{mg}^{-1}\right)$ or 12AS (11.6\% Bti, strain AM 65-52; 1200 ITU mg $\left.^{-1}\right)$. Application rates are given in Table S1. They were equal or below the maximum authorized rate ( $1 \mathrm{~kg} \mathrm{ha}^{-1}$ and $2.5 \mathrm{~L} \mathrm{ha}^{-1}$ for WDG and 12AS, respectively) falling, for most of them, within the suggested rate range for mosquito control (125-500 $\mathrm{g} \mathrm{ha}^{-1}$ and $0.35-2.5 \mathrm{~L} \mathrm{ha}^{-1}$ for WDG and 12AS, respectively). VectoBac ${ }^{\circledR}$ was diluted into tap water in portable sprayers for application at the water surface, thus limiting spray drift. Treatments were performed by qualified personnel of the services in charge of mosquito control in each administrative district where the study was conducted. A few days after treatment, Bti efficacy was checked by mosquito control operators, and most frequently reported as ca. $90 \%$ mosquito larval mortality.

According to the best mosquito control practices (e.g., ECDC, 2014), the treatment procedure requires that VectoBac ${ }^{\circledR}$ is applied only if the actual abundance of mosquito larvae exceeds a given threshold (Carron et al., 2003). This, and the occurrence of flooding periods of

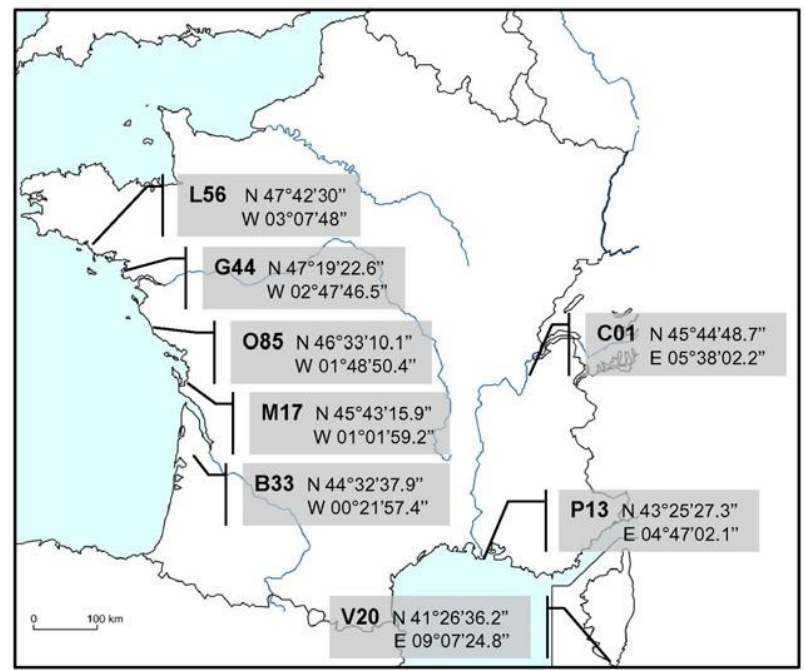

Fig. 1. Location of the eightstudy sites wherenon target aquaticinvertebratecommunities were monitored for potential effects of VectoBac ${ }^{\circledR}$ WDG or 12AS. See Table S1 for site description. variable frequency and duration in the different study sites, resulted in a gradient of treatment pressure (Fig. 2). Given that larvicide treatment frequency differed among sites, the time since VectoBac ${ }^{\circledR}$ application was used asa variable in the statistical analyses.

\subsection{Invertebrate community sampling and analysis}

Invertebrate sampling was performed at regular time intervals after VectoBac ${ }^{\circledR}$ application (TableS2), to allow the examination of potential short- and long-term effects. Invertebrates were sampled in water and sediment of the control and treated areas (five replicates in each area) using a cylindrical stainless steel corer (internal diameter $=16.5 \mathrm{~cm}$, surface $=213.72 \mathrm{~cm}^{2}$ ), as previously described (Lagadic et al., 2014). Care was taken to throw the corer at a reasonable distance from the operator, to avoid fast swimmers to escape. Samples were immediately preserved in ethanol $(70 \% \mathrm{v} / \mathrm{v}$, final concentration). In the laboratory, they were passed through sieves of decreasing mesh size $(8,4,2,1,0.5,0.25 \mathrm{~mm})$, and invertebrates were subsequently enumerated and identified to the lowest feasible taxonomic level under a stereomicroscope.

\subsection{Environmental variables}

Environmental factors that are known as drivers of aquatic invertebrate community changes were measured. Among them, flooding, which is an inherent characteristic of mosquito breeding sites in wetlands, was more specifically considered in terms of both frequency (i.e. number over the study period) and duration. In both control and treated areas, at each location where invertebrates were sampled, water depth, temperature, dissolved oxygen content and saturation percent, salinity, and $\mathrm{pH}$ were measured as previously described (Lagadic et al., 2014). In addition, the presence of water in control and treated areas was recorded weekly to monthly. Invertebrates were sampled in both areas only when the entire study site was flooded. For each invertebrate sampling date/area, a time-since-flooding variable (in days) was determined between the sampling date and the beginning of the most recent flooding period after a drought event.

\subsection{Statistical analysis}

Potential effects of Bti on communities were analysed in each site (site-by-site analysis) as well as across all sites (global analysis). The site-by-site analysis focused on taxa responsible for community difference between control and treated areas across time using abundance data. In this context, a particular attention was devoted to chironomids. The global analysis consisted of two analyses: (i) potential effects of $B t i$ on univariate community metrics (e.g., taxonomic richness) and (ii) the relationship between environmental variables as well as time since

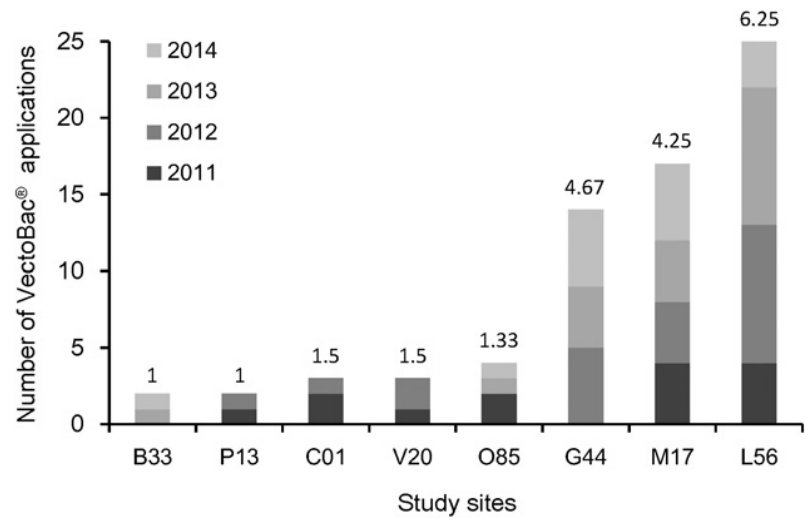

Fig. 2. Representation of the gradient of VectoBac ${ }^{\circledR}$ treatment pressure over the study sites. Values above the histogram bars represent the mean numbers of treatments per year in each site. See Table S1 and Fig. 1 for site codes and location, respectively. 
Vectobac ${ }^{\circledR}$ application, and community differences between treated and control areas measured as distance metrics. Note that the analyses focused on the detection of potential effects of $B t i$, and analysing the relevance of other environmental variables for taxon turn-over across study sites and time was out of the scope of this study. However, conductivity, oxygen content and flooding appeared as the dominant variables explaining taxon variability across sites and time in a multivariate regression tree analysis (De'Ath, 2002) (Fig. S2).

Prior to analysis, the environmental variables were checked for intercorrelation using the Pearson correlation coefficient and visualisation. Salinity and oxygen content were omitted from analysis because of high intercorrelation ( $r=0.99$ and $r=0.82$, respectively) with conductivity and oxygen saturation. Paired $t$-tests were used to screen for differences in environmental variables between control and treated areas for each site. The assumptions of normal distribution and variance homogeneity were met for all variables and treatments, except for a few cases where the Welch approximation was used to account for variance heterogeneity. p values were adjusted for multiple testing of variables from a site using Holm's correction (Holm, 1979).

\subsubsection{Global analyses}

As outlined above, two types of analyses were conducted, that focused on different community descriptors: (i) univariate analysis of community metrics, and (ii) distance-based multivariate community analysis.

In univariate community analysis, differences between control and treated areas for community metrics (Clarke and Warwick, 2001), i.e., taxonomic richness $(\mathrm{S})$, Shannon's diversity index $\left(\mathrm{H}^{\prime}\right)$, and total and chironomid abundances were analysed using generalized linear mixed model (GLMM) with appropriate error distributions (Gaussian and negative binomial for counts) (Bolker et al., 2009). Samples within site were modelled as random factors, time and treatment as fixed factors. Models were inspected graphically, and differences were tested using Likelihood-Ratio-Tests.

Prior to distance-based multivariatecommunity analysis, taxa abundance data were double-square-root-transformed to downweight highly abundant taxa (Szöcs et al., 2015). Two global analyses of environmental and invertebrate abundance data were performed for $(i)$ the complete community and (ii) the chironomid community, considered as the most-at-risk group. For both analyses, it was checked whether differences in the invertebrate or chironomid communities between control and treated areas could be explained by an environmental variable or by the time since VectoBac ${ }^{\circledR}$ application.

Before analysis, rare taxa were removed to increase the statistical power for finding statistical differences between control and treated areas, thus decreasing the risk of false negatives (i.e., not detecting a true effect). Indeed, without this step (results not shown), the noise in almost all statistical analyses did not allow testing the significance of between-area differences. Thus, for the complete community analysis (166 taxa), 40 taxa that occurred in b 1\% (i.e., 3) of the 246 samples were removed from the dataset. For taxa found in b5\% (i.e., 14) of the 246 samples, the difference in the presence between control and treated areas was calculated. An additional group of 52 taxa, for which the difference in their presences between control and treated areas was b 2, was omitted from community analysis to increase the power of detecting community differences. For the analysis of the chironomid community, no taxa were removed since they all occurred in N1\% of samples.

Community dissimilarity was computed as the Bray Curtis dissimilarity index for the communities sampled in the control and treated areas of a given site, paired by the sampling time. To examine whether the community dissimilarity was driven by VectoBac ${ }^{\circledR}$ treatment or by other environmental variables, linear mixed effect models (LMM) were used, with community dissimilarity as the response variable and site as the random factor. The fixed factors (i.e., time since VectoBac ${ }^{\circledR}$ application or environmental variables) entered the analysis as paired difference between control and treated areas in the respective study site, following the rationale that a larger difference in an environmental variable that drives community difference should coincide with higher community dissimilarity. In addition, the community dissimilarity between control and treated areas just after treatment (up to 11 days given that the residual activity of Bti can last up to 11 days - Su and Mulla, 1999b; Lima et al., 2005; Rydzanicz et al., 2010) was compared to the dissimilarity at least 180 days after the last treatment (following the rationale that $B t i$ spore persistence has been observed up to about 3 months after treatment -Hajaij et al., 2005; Duchet et al., 2014 - and allowing for an additional 3-month period for potential recovery) using LMM. These time thresholds resulted in a fairly balanced sample distribution ( $\geq 11$ days after treatment: 29 samples; $\geq 180$ days after treatment: 32 samples).

\subsubsection{Site-by-site analyses}

To further scrutinize differences between control and treated areas, community metrics were compared using GLM at each site and sampling date separately. Variations of invertebrate abundance were analysed using Principal Response Curves (PRC; van den Brink and ter Braak, 1999) which corresponds to a redundancy analysis (RDA) for comparison of control and treated communities over time. For each sampling date, differences between control and treated areas were tested using Monte Carlo permutations (999 permutations) (Legendre et al., 2011). For a given site, taxa that occurred in b $1 \%$ of the samples were removed from the dataset, and abundance data were Hellingertransformed, to avoid problems associated with the use of linear methods for ecological data (Legendre and Gallagher, 2001).

All statistical analyses were conducted in R 3.1.1. Multivariate Analysis using the vegan package (Oksanen et al., 2013). LMM and GLMM were fitted using the lme4 (Bates et al., 2015) and ADMB (Fournier et al., 2012).

\section{Results}

\subsection{Environmental variables}

The treatment and control areas of sites C01, G44, P13 and V20 were similar with respect to all measured environmental variables (all adjusted $\mathrm{pN} 0.05$ in each site, paired $t$-tests). In site M17, water depth in control and treated areas differed significantly (adjusted $p=0.02$, paired $t$ test). For site L56, control and treated areas exhibited significant differences in water depth, $\mathrm{pH}$, and temperature (all adjusted $\mathrm{pb} 0.05$, paired $t$-tests). The control and treated areas of site 085 differed significantly in water depth, flooding and conductivity (all adjusted $\mathrm{p} \mathrm{b} 0.04$, paired $t$ tests). In site B33, control and treated areas differed significantly in flooding, temperature and conductivity (all adjusted $\mathrm{p} b 0.02$, paired $t$ tests). Overall, the study sites followed a gradient of conductivity (Fig. S3).

\subsection{Global analysis of invertebrate communities}

The list of taxa found in the samples from each study site is given in Table S3. Total chironomid abundance was the only community descriptor that showed a statistically significant difference between control and treated areas. Chironomid counts were slightly increased in VectoBac ${ }^{\circledR}-$ treated areas $(+1.32$ [95\% CI: 1.02-1.71] compared to control areas). No differences were found for the other descriptors (Fig. S4 and Table S4). Moreover, all descriptors showed a ten-fold higher variance between areas than between samples.

The dissimilarity in the entire aquatic invertebrate communities did not exhibit a significant relationship with time since VectoBac ${ }^{\circledR}$ application ( $p=0.53, t$-test for coefficient in LMM, $n=123$, groups $=8$ ) or with any other environmental variable (Fig. 3), although conductivity and oxygen saturation exhibited the lowest $p$ values $(\mathrm{p}=0.11$ and $0.12, t$-test for coefficient in LMM, $\mathrm{n}=123$, groups $=8$ ). Similarly, in restricted statistical models, the variable 'time since VectoBac ${ }^{\circledR}$ application' 
was not significant (i) for the three sites where the control area had never been treated (M17, L56 and C01; p $=0.27, t$-test for treatment coefficient in LMM, $\mathrm{n}=62$, groups $=3$ ) and (ii) for the site C01 where the control area had never been treated and for which environmental variables exhibited no significant between-area differences $(p=0.76, t$-test for coefficient in linear model, $\mathrm{r}^{2}=0.01, \mathrm{n}=12$ ). Moreover, no temporal pattern was detected since the dissimilarity for samples taken directly after treatment was similar to that of samples taken at least 180 days after treatment (Fig. $4 \mathrm{~A} ; \mathrm{p}=0.8$, $t$-test for coefficient in $\mathrm{LMM}, \mathrm{n}=46$, groups $=8$ ).

The chironomid community comprised six taxa (Chironomini, Corynoneurinae, Orthocladiinae, Tanypodinae, Tanytarsinii, unidentified Chironomidae pupae). The between-area dissimilarity in the chironomid communities was significantly related to the difference in time since flooding (Fig. 5A; $\mathrm{p}=0.002, t$-test for coefficient in LMM, $\mathrm{n}=119$, groups $=8$ ) but not to the time since VectoBac ${ }^{\circledR}$ application (Fig. 5B) or to any other environmental variable (all $\mathrm{p} \mathrm{N} 0.48, t$-test for coefficient in LMM, $n=119$, groups $=8$ ). When the statistical model was restricted to the three sites (M17, L56 and C01) where the control area had never been treated, no statistically significant relationship with the time since VectoBac ${ }^{\circledR}$ application was found $(p=0.95, t$-test for treatment coefficient in LMM, $\mathrm{n}=62$, groups $=3$ ).

When restricting the model to the site $\mathrm{C} 01$, the chironomid community dissimilarity was significantly related to VectoBac ${ }^{\circledR}$ application ( $\mathrm{p}=0.02$, $t$-test for coefficient in linear model, $\mathrm{r}^{2}=0.36, \mathrm{n}=12$ ). However, the dissimilarity increased with time since VectoBac ${ }^{\circledR}$ application (Fig.6A).Furthermore, the temporal pattern of the chironomid community dissimilarities showed no clear decline in relation to VectoBac ${ }^{\circledR}$ treatment (Fig. 6B). In addition, no other site displayed a relationship with time since VectoBac ${ }^{\circledR}$ treatment (all p N 0.31, $t$-test for coefficient in linear model). Finally, the chironomid community dissimilarity for samples taken directly after treatment was similar to that of samples taken at least 180 days after treatment (Fig. $4 \mathrm{~B} ; \mathrm{p}=0.41$, $t$-test for coefficient in LMM, $\mathrm{n}=45$, groups $=8$ ).

\subsection{Site-by-site analysis}

Responses of community descriptors to VectoBac $\AA^{\circledR}$ treatment differed between sites and time (Fig. S5). The Shannon index showed the least effects. In the treated area, total abundance increased in sites B33 and P13, and decreased in sites C01, G44 and V20. All other sites showed fluctuating responses. Taxonomic richness increased in the treated areas in sites B33, P13 and O85, and decreased in sites C01 and L56. All other sites showed fluctuating responses. Chironomid counts

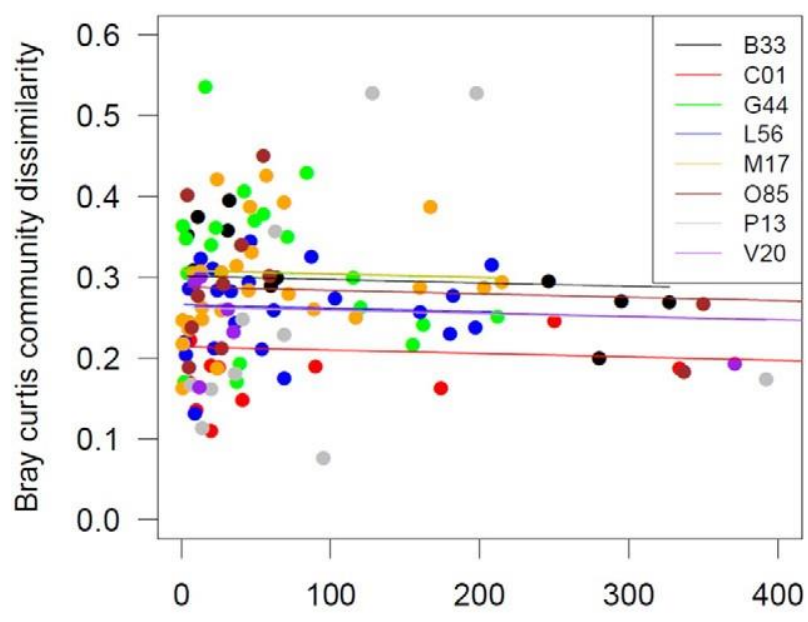

Time since treatment

Fig. 3. Changes over time (in days) of Bray-Curtis dissimilarity of non-target invertebrate communities between control and VectoBac ${ }^{\circledR}$-treated areas in the eight study sites. The lines correspond to the linear mixed effect model. increased in treated areas in sites B33 and P13, and decreased in site V20. All other sites showed fluctuating responses.

PRC analyses showed significant differences in invertebrate abundance between control and treated areas in all study sites except V20 (Fig.S6 and TableS5). Monte-Carlo permutation tests indicated that, depending on the site, 2.3 to $14 \%$ of total variance was captured by the first PRCaxis. Overall, time explained $26-53 \%$ of the variance whereas only $8-23 \%$ could be attributed to treatment (Table S5). Analysis of taxa weights $\left(b_{k}\right)$, which reflects taxon contribution to between-area differences, did not indicate that a particular taxa consistently occurred at lower abundances in treated areas (Fig. S6). For example, Proasellus $\mathrm{sp}$. was found at lower abundance in the treated area of site B33, but at higher abundance in the treated area of site O85. Similarly, Ostracods were less abundant in the treated area of site G44, but were more abundant in the treated areas of sites B33 and P13. Chironomids were less abundant in the treated area of site P13, but were more abundant in the treated areas of sites G44 and B33. In sites M17 and C01, differences in the abundance of the same taxa (e.g., oligochaetes, various crustaceans, chironomini) between areas varied with time.

\section{Discussion}

This study supports the contention that, when following recommended application rates and best mosquito control practices, treatments with the VectoBac ${ }^{\circledR}$ WDG and 12AS formulations of Bti have no detectable influence on the dynamics of non-target aquatic invertebrate communities, including chironomids, in coastal and continental wetlands, where environmental factors are the driving forces of these communities (Fig. S2). This was shown for eight study sites with a wide geographical distribution encompassing a range of environmental conditions. In particular, vegetation typology (Table S1), flooding frequency and duration (Fig. S1) and salinity/conductivity (Fig. S3) followed gradients that covered the conditions encountered in the main types of natural mosquito breeding sites. In addition, the gradient of Bti treatment pressure over the study sites (Fig. 2) realistically reflected adaptation of mosquito control practices to local requirements. It is therefore highly representative of the vulnerability, and hence the response potential, of non-target invertebrate communities to $\mathrm{Bti}$.

Over the study period, differences occurred between control and VectoBac ${ }^{\circledR}$-treated areas in most of the study sites, both for community metrics (e.g., taxonomic richness) and taxon abundance. However, even in site L56 where they were more often lower in the treated area than the control, they exhibited no association with larvicide treatments. Similarly, the discrepancies between control and treated areas that were shown by the PRC analysis could not be attributed to VectoBac ${ }^{\circledR}$ treatments. Indeed, the taxa which were most indicative for differences between control and treated areas (with regard to their position on the $b_{k}$ axis; Fig. S6) varied with site and time (in sites M17, C01 and V20) and most of them are known to be relatively insensitive to $B$ ti (Boisvert and Boisvert, 2000), whereas the most-at-risk group of chironomids largely remained unaffected. For example, Nereis (Hediste) diversicolor and nematodes were found at lower abundances in the treated area of site L56. However, Nereidae are known to be insensitive to Bti (Reish et al., 1985; Fourcy et al., 2002), and for nematodes, the only $B t$ toxins which were shown to be toxic are Cry5B and Cry21, which do not exist in Bti (Bravo et al., 2011).

Consistently, the global dissimilarity analysis showed that invertebrate community variations between control and treated areas were not related to the application of the two Bti formulations (Fig. 3). In addition, no change in dissimilarity between control and treated areas was observed immediately after VectoBac® application when compared to dissimilarity at least 180 days after treatment. This indicates the absence of immediate effects that could be assigned to direct toxicity of Bti to non-target taxa. In addition, long-term assessment showed that indirect effects, including those which could potentially be linked to the reduction of larval mosquito populations, were not found over the whole 

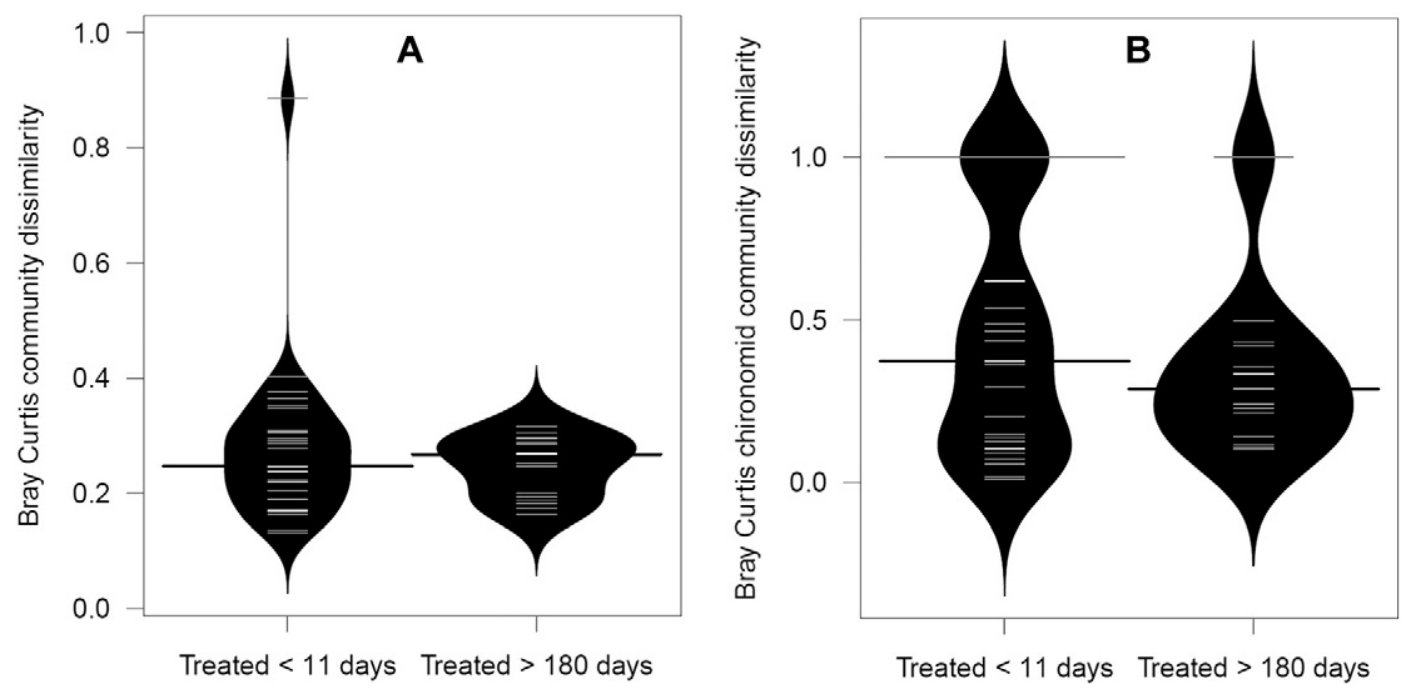

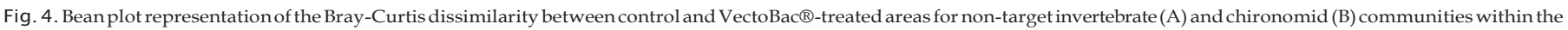
11 days and 6 months following application. See Kampstra (2008) for details on bean plots.

study period in all sites. Overall, these results support the absence of relevanteffects of $B$ tion aquatic food webs, as already evidenced by a number of field studies in wetlands (Painter et al., 1996; Blum et al., 1997; Balcer et al., 1999; Niemi et al., 1999; Lagadic et al., 2014; Fayolle et al., 2015).

Of particular interest were the variations in the abundance of chironomids between control and VectoBac ${ }^{\circledR}$-treated areas in the different study sites. Within the chironomid community, the two taxa known as the most sensitive to $B t i$, namely Chironomini and Orthocladiinae, were found in all sites. They showed no consistent deviation from control across sites (P13, G44 and B33), or their deviation from control even varied over time within a given site (M17 and C01). Consistently, dissimilarity analysis showed that between-area differences in the abundance of chironomids were not linked to VectoBac ${ }^{\circledR}$ (Fig. 5B), and no immediate effect of Bti on chironomids was found (Fig. 4B). The study site C01 deserves particular attention because it was the only site where the control area had never been treated and for which all environmental variables were similar between control and treated areas. In this site, between-area dissimilarity of the chironomid communities was significantly linked to VectoBac ${ }^{\circledR}$ WDG application, albeit it exhibited no clear response to treatments. In fact, the presumed most sensitive groups of Chironomini and Orthocladiinae were either present in both control and treated areas at all but one sampling date, or merely absent in both areas. Overall, VectoBac ${ }$ WDG applications in site C01 were not associated with clear effect on chironomids. However, given that chironomids were not identified to species level, effects of Bti on individual species cannotberuled out, although previousstudies at higher taxonomic resolution (i.e., species level) did not detect effects at VectoBac ${ }^{\circledR}$ application rates recommended for mosquito control (Lundström et al., 2010a; Duchet et al., 2015). Note that another study that claimed effects of Bti on chironomids (Poulin, 2012) relied on data obtained at a much higher level of taxonomic resolution than those achieved in the present study.

The analysis of chironomid communities from eight different study sites representing a wide variety of ecological conditions showed that appropriate dosages of $B t i$ can efficiently control mosquito larval populations (up to $90 \%$ reduction) with no detectable effects on non-biting midge larvae. This is fully consistent with the conclusions from shortterm semi-field experiments (Charbonneau et al., 1994; Liber et al., 1998; Pont et al., 1999; Russell et al., 2009; Duchet et al., 2015) and from field studies conducted over multiple years (Barnes and Chapman, 1998; Balcer et al., 1999; Caquet et al., 2011; Lundström et al., 2010a,b; Persson Vinnersten et al., 2010; Lagadic et al., 2014). Most of these studies, as well as those reporting transient effects on chironomids (Hershey et al., 1995, 1998; Niemi et al., 1999), recognized the predominant role of natural environmental variables in invertebrate

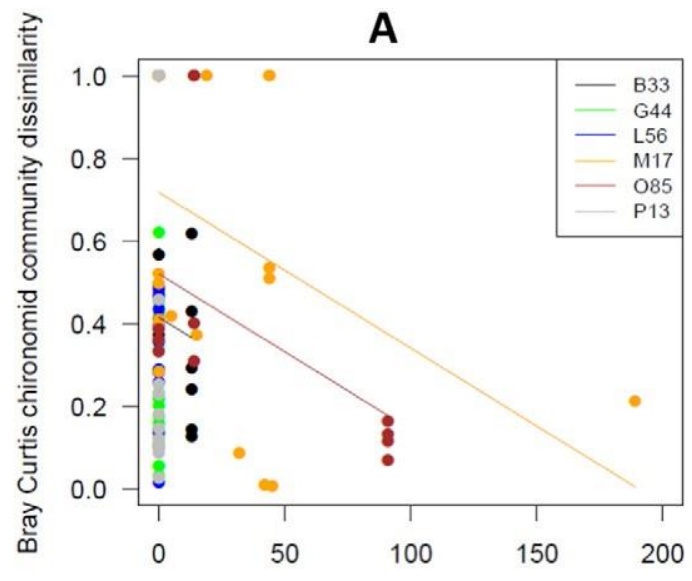

Difference in time since flooding

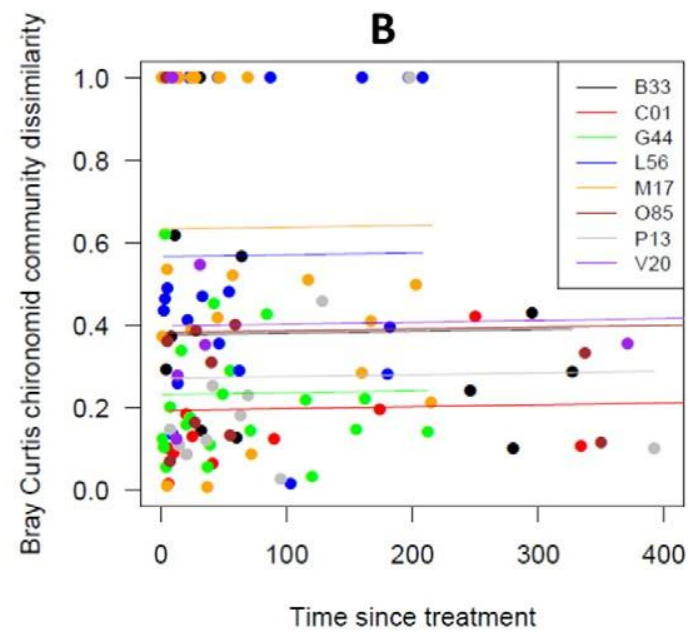

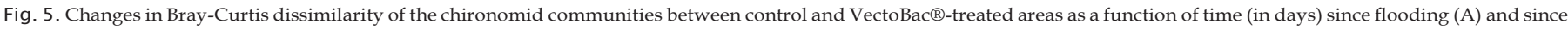
larvicide application (B) in all study sites. The lines correspond to the linear mixed effect model. See Table S1 and Fig. 1 for site codes and location, respectively. 

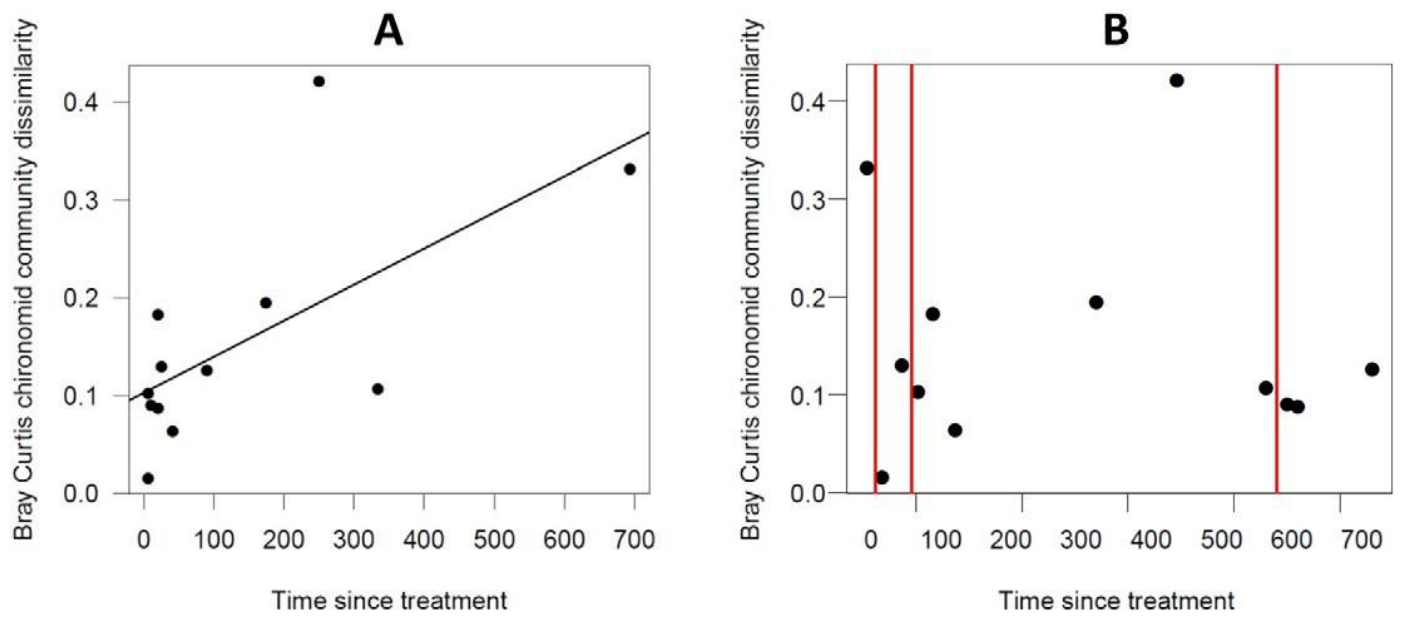

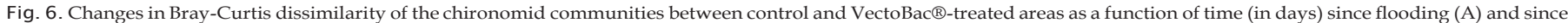
larvicide application (B) in site C01. In A, the lines correspond to the linear mixed effect model. In B, vertical lines indicate time points of VectoBac ${ }^{8}$ applications.

community dynamics. In the present study, control and treated areas were selected on the basis of similar ecological conditions. Nevertheless, in half of the study sites, several physicochemical parameters (water depth, temperature, conductivity, $\mathrm{pH}$, flooding) differed significantly between control and treated areas. Scrutinising the effects of environmental variables in individual sites was beyond the scope of this study and it is likely that the significant differences between sites were responsible for the significant differences in communities observed in the analysis of individual sites. However, in the global analysis across all sites, flooding could be statistically significantly linked to variations in chironomid communities (Fig. 5A), though conductivity and oxygen saturation were identified as additional major drivers of the communities (Fig. S2). Indeed, most of the study sites were influenced by flooding, more precisely by dramatic changes in water level, from flooding to drought, with site-dependent differences in frequency and duration (Fig. S1). Flooding events strongly influenced the composition and abundance of invertebrate communities, especially in the sites connected to the ocean where they coincide with immigration of individuals, resulting in substantial stochastic changes in population densities. Local hydrodynamic conditions may influence flooding frequency and duration, so that discrepancies between control and treated areas may occur not only in terms of species composition and abundance but also with respect to microhabitat conditions (e.g., conductivity/salinity), which in turn will be more suitable for some species than for others. Both flooding frequency and duration should therefore be included in the survey of non-target aquatic invertebrate communities exposed to Bti because they may induce community changes (see e.g., Scrimgeour and Winterbourn, 1989; Boix et al., 2010), which could be erroneously attributed to the larvicide.

\section{Conclusion}

This study is the first field investigation ever conducted at such a large, national geographic scale on the effects of $B t i$ on aquatic invertebrates in coastal and continental wetlands covering a wide range of ecological conditions. It shows that, when recommended application rates and best practices for mosquito control are strictly followed, the use of the VectoBac ${ }^{\circledR}$ WDG and 12AS formulations of Bti can be considered as safe for non-target aquatic invertebrates, including chironomids. The best level of protection of non-target invertebrates relies upon the reduction of $B t i$ dosages to thresholds which provide an efficient control of mosquito populations and minimize undesirable effects on the environment. This was the main aim of the LIFE + Programme IMCM (Integrated Mosquito Control and Management) in which the present study was included. Reduction of Bti dosages is however not affordable in every situation (e.g., dense vegetation, late development stages and high densities of larvae, water temperature and depth, ultra-low volume application by aircraft). The use of reduced dosages of $B t i$ should therefore be complemented by other mosquito population control methods (e.g., reduction of larval mosquito habitats, use of native mosquito predators, management of vegetation in wetland) in so-called Integrated Mosquito Management programmes (see e.g., Washington State Department of Ecology, 2004; FMCA-FDACS, 2012; WHO, 2012).

\section{Conflict of interest statement}

The authors have no conflicts of interest to disclose.

\section{Acknowledgements}

We thank A. Roucaute, S. Harnois, C. Geret, M.-A. Liger, Y. Gautier, M. Bérot (INRA, Rennes), R. Garnier, A. Daubercies and I. Simonnet (IMBE, Aix-Marseille) for their assistance in invertebrate field sampling, identification, and enumeration. Our thanks are extended to the personnel of the services in charge of mosquito control which were involved in this study, more specifically A. Marie, M. Hermantier, J.-B. Ferré (EIDMéditerranée) and G. Besnard (EID-Rhône-Alpes). Our thanks are also due to T. Caquet (INRA, Rennes) for his contribution to the early steps of the study. We gratefully acknowledge the financial support from the Conseils Départementaux of Morbihan, Loire-Atlantique, Vendée, Charente-Maritime and Gironde for the investigations conducted along the French Atlantic coast and from the LIFE+ Programme IMCM (Integrated Mosquito Control and Management) No. LIFE08 ENV/F/ 000488 for the studies conducted in the other sites.

\section{Appendix A. Supplementary data}

Supplementary data to this article can be found online at http://dx. doi.org/10.1016/j.scitotenv.2016.02.096.

\section{References}

Ali, A., Lobinske, R.L., 2002. Laboratory and field use of Bacillus thuringiensisssp.israelensis against pestiferous Chironomidae (Diptera): an assessment. Kuala Lumpur, Malaysia: Proc 3rd Int Conf on Biopesticides, pp. 71-79.

Ali, A., Baggs, R.D., Stewart, J.P., 1981. Susceptibility of some Florida chironomids and mosquitoes to various formulations of Bacillus thuringiensis serovar. israelensis. J. Econ. Entomol. 74, 672-677.

Balcer, M.D.,Schmude, K.I.,Snitgen,J., Lima, A.R.,1999. Long-termeffects of themosquito control agents Bti (Bacillus thuringiensis israelensis) and methoprene on non-target 
macro-invertebrates in wetlands in Wright County, Minnesota (1997-1998). St. Paul, Minnesota: Report to Metropolitan Mosquito Control District.

Barnes, P.B., Chapman, M.G., 1998. Effects of the Larvicide VectoBac on Assemblages of Benthic Invertebrates in Bicentennial Park. Centre for Research on Ecological Impacts of Coastal Cities, Sydney, Australia.

Bates, D., Mächler, M., Bolker, B., Walker, S., 2015. Fitting linear mixed-effects models using lme4. J. Stat. Softw. 67(1) (http://doi.org/10.18637/jss.v067.i01).

Blum, S., Basedow, Th., Becker, N., 1997. Culicidae(Diptera) in the diet of predatory stages of anurans (Amphibia) in humid biotopes of the Rhine Valley in Germany. J. Vector Contr. 22, 23-29.

Boisvert, M., Boisvert, J., 2000. Effects of Bacillus thuringiensis var. israelensis on target and nontarget organisms: a review of laboratory and field experiments. Biocontrol Sci. Tech. 10, 517-561.

Boix, D., García-Berthou, E., Gascón, S., Benejam, L., Tornés, E., Sala, J., Benito, J., Munné, A., Solà, C., Sabater, S., 2010. Response of community structure to sustained drought in Mediterranean rivers. J. Hydrol. 383, 135-146.

Bolker, B., Brooks, M., Clark, C., Geange, S., Poulsen, J., Stevens, M.H., White, J.S., 2009. Generalized linear mixed models: a practical guide for ecology and evolution. Trends Ecol. Evol. 24, 127-135.

Bravo, A., Likitvivatanavong, S., Gill, S.S., Soberón, M., 2011. Bacillus thuringiensis: a story of a successful bioinsecticide. Insect Biochem. Mol. Biol. 41, 423-431.

Caquet, T., Roucaute, M., Le Goff, P., Lagadic, L., 2011. Effects of repeated field applications of two formulations of Bacillus thuringiensis var. israelensis on non-target saltmarsh invertebrates in Atlantic coastal wetlands. Ecotoxicol. Environ. Saf. 74, 1122-1130.

Carron, A., Duchet, C., Gaven, B., Lagneau, C., 2003. An easy field method for estimating the abundance of culicid larval instars. J. Am. Mosq. Control Assoc. 19, 353-360.

Charbonneau, C.S., Drobney, R.D., Rabeni, C.F. 1994. Effects of Bacillus thuringiensis on nontarget benthic organisms in a lentic habitat and factors affecting the efficacy of the larvicide. Environ. Toxicol. Chem. 13, 267-279.

Clarke, K.R., Warwick, R.M., 2001. Change in Marine Communities: An Approach to Statistical Analysis and Interpretation. second ed. PRIMER-E, Plymouth, UK.

Clements, W.H., Kashian, D.R., Kiffney, P.M., Zuellig, R.E., 2015. Perspectives on the context-dependency of stream community responses to contaminants. Freshw. Biol. http://dx.doi.org/10.1111/fwb.12599.

Crickmore, N., 2005. Beyond the spore - past and future developments of Bacillus thuringiensis as a biopesticide. J. Appl. Microbiol. 101, 616-619.

De'Ath, G., 2002. Multivariate regression trees: a new technique for modeling species-environment relationships. Ecology 83, 1105-1117.

Després, L., Lagneau, C., Frutos, R., 2011. Using the bio-insecticide Bacillus thuringiensis israelensis in mosquito control. In: Stoytcheva, M. (Ed.), Pesticides in the Modern World - Pests Control and Pesticides Exposure and Toxicity Assessment. InTech, Rijeka, Croatia, pp. 93-126.

Duchet, C., Tetreau, G., Marie, A., Rey, D., Besnard, G., Perrin, Y., Paris, M., David, J.-P., Lagneau, C., Després, L., 2014. Persistence and recycling of bioinsecticidal Bacillus thuringiensis subsp. israelensis spores in contrasting environments: evidence from field monitoring and laboratory experiments. Microb. Ecol. 67, 576-586.

Duchet, C., Franquet, E., Lagadic, L., Lagneau, C., 2015. Effects of Bacillus thuringiensis israelensis and spinosad on adult emergence of the non-biting midges Polypedilum nubifer (Skuse) and Tanytarsus curticornis Kieffer (Diptera: Chironomidae) in coastal wetlands. Ecotoxicol. Environ. Saf. 115, 272-278.

Duguma, D., Hall, M.W., Rugman-Jones, P., Stouthamer, R., Neufeld, J.D., Walton, W.E., 2015. Microbial communities and nutrient dynamics in experimental microcosm are altered after the application of a high dose of Bti. J. Appl. Ecol. 52, 763-773.

ECDC - European Centre for Disease Prevention and Control, 2014,. Guidelines for the Surveillance of Native Mosquitoes in Europe. ECDC, Stockholm, Sweden.

Fayolle, S., Bertrand, C., Logez, M., Franquet, E., 2015. Does mosquito control by Bti affect the phytoplankton community? A 5-year study in Camargue temporary wetlands (France). Ann. Limnol. - Int. J. Limnol. 51, 189-198.

FMCA-FDACS, 2012. Best Management Practices for Integrated Mosquito Management. Florida Mosquito Control Association, Florida Department of Agriculture and Consumer Services.

Fourcy, D., Jumel, A., Heydorff, M., Lagadic, L., 2002. Esterases as biomarkers in Nerei (Hediste) diversicolor exposed to temephos and Bacillus thuringiensis var. israelensis used for mosquito control in coastal wetlands of Morbihan (Brittany, France). Mar. Environ. Res. 54, 755-759.

Fournier, D. A., Skaug, H.J., Ancheta, J., Ianelli, J., Magnusson, A., Maunder, M., Nielsen, A., Sibert, J., 2012. AD Model Builder: using automatic differentiation for statistical inference of highly parameterized complex nonlinear models. Optim. Methods Softw. 27, 233-249.

Hajaij, M., Carron, A., Deleuze, J., Gaven, B., Setier-Rio, M.-L., Vigo, G., Thiéry, I., NielsenLeRoux, C., Lagneau, C., 2005. Low persistence of Bacillus thuringiensis serova israelensis spores in four mosquito biotopes of a salt marsh in southern France. Microb. Ecol. 50, 475-487.

Hanowski, J., Niemi, G., Lima, A., Regal, R., 1997a. Response of breeding birds to mosquito control treatments of wetlands. Wetlands 17, 485-492.

Hanowski, J.M., Niemi, G.J., Lima, A.R., Regal, R.R., 1997b. Do mosquito control treatment of wetlands affect red-winged blackbird (Agelaius phoeniceus) growth, reproduction, or behavior? Environ. Toxicol. Chem. 16, 1014-1019.

Hershey, A.E., Shannon, L., Axler, R., Ernst, C., Mickelson, P., 1995. Effects of methoprene and Bti (Bacillus thuringiensis var. israelensis) on non-target insects. Hydrobiologia 308, 219-227.

Hershey, A.E., Lima, A.R., Niemi, G.J., Regal, R.R., 1998. Effects of Bacillus thuringiensis israelensis (Bti) and methoprene on non-target macroinvertebrates in Minnesota wetlands. Ecol. Appl. 8, 41-60.

Heurteaux, P., 1999. A propos des moustiques de Camargue... et de la démoustication. Le Courrier de la Nature 177, 17-21.
Holm, S., 1979. A simple sequentially rejective multiple test procedure. Scand. J. Stat. 6 , 65-70.

Kampstra, P., 2008. Beanplot: a boxplot alternative for visual comparison of distributions. R J. 1-9.

Lacey, L.A., Merritt, R.W., 2004. The safety of bacterial microbial agents used for black fly and mosquito control in aquatic environments. In: Hokkanen, H.M.T., Hajek, A.E. (Eds.), Environmental Impacts of Microbial Insecticides: Need and Methods for Risk Assessment. Kluwer Academic Publishers, Dordrecht, The Netherlands, pp. 151-168.

Lagadic, L., Roucaute, M., Caquet, T., 2014. Bti sprays do not adversely affect non-target aquatic invertebrates in French Atlantic coastal wetlands. J. Appl. Ecol. 51, 102-113.

Land, M., Miljand, M., 2014. Biological Control of Mosquitoes Using Bacillus thuringiensis israelensis: A Pilot Study of Effects on Target Organisms, Non-target Organisms and Humans. Mistra EviEM, Stockholm, Sweden.

Legendre, P., Gallagher, E.D., 2001. Ecologically meaningful transformations for ordination of species data. Oecologia 129, 271-280.

Legendre, P., Oksanen, J., ter Braak, C.J.F., 2011. Testing the significance of canonical axes in redundancy analysis. Methods Ecol. Evol. 2, 269-277.

Liber, K., Schmude, K.L., Rau, D.M., 1998. Toxicity of Bacillus thuringiensis var. israelensis to chironomids in pond mesocosms. Ecotoxicology 7, 343-354.

Lima, J.B.P., de Melo, N.V., Valle, D., 2005. Persistence of Vectobac WDG and Metoprag S$2 \mathrm{G}$ against Aedes aegypti larvae using a semi-field bioassay in Rio de Janeiro, Brazil. Rev. Inst. Med. Trop. São Paulo 47, 7-12.

Lundström, J.O., Brodin, Y., Schäfer, M.L., Persson Vinnersten, T.Z.,Östman, Ö., 2010a. High species richness of Chironomidae (Diptera) in temporary flooded wetlands associated with high species turn-over rates. Bull. Entomol. Res. 100, 433-444.

Lundström, J.O., Schäfer, M.L., Petersson, E., Persson Vinnersten, T.Z., Landin, J., Brodin, Y., 2010b. Production of wetland Chironomidae (Diptera) and the effects of using Bacillus thuringiensis israelensis for mosquito control. Bull. Entomol. Res. 100, 117-125.

Maletz, S., Wollenweber, M., Kubiak, K., Müller, A., Schmitz, S., Maier, D., Hecker, M., Hollert, H., 2015. Investigation of potential endocrine disrupting effects of mosquito larvicidal Bacillus thuringiensis israelensis (Bti) formulations. Sci. Total Environ. 536, 729-738.

Medlock, J.M., Leach, S.A., 2015. Effect of climate change on vector-borne disease risk in the UK. Lancet Infect. Dis. 15, 721-730.

Niemi, G.J., Hershey, A.E., Shannon, L., Hanowski, J.M., Lima, A., Axler, R.P., Regal, R.R., 1999. Ecological effects of mosquito control on zooplankton, insects, and birds. Environ. Toxicol. Chem. 18, 549-559.

Oksanen, J., FG, Blanchet, Kindt, R., Legendre, P., PR, Minchin, RB, O'Hara, GL, Simpson, Solymos, P., MHH, Steven, Wagner, H., 2013. Vegan 2.2-0. Community ecology package. http://cran.r-project.org/web/packages/vegan.

Painter, M.K., Tennessen, K.J., Richardson, T.D., 1996. Effects of repeated applications of Bacillus thuringiensis israelensis on the mosquito predator Erythemis simplicicollis (Odonata: Libellulidae) from hatching to final instar. Environ. Entomol. 25, 184-191.

Persson Vinnersten, T.Z., Lundström, J.O., Schäfer, M.L., Petersson, E., Landin, J., 2010. A sixyear study of insect emergence from temporary flooded wetlands in central Sweden, with and without Bti-based mosquito control. Bull. Entomol. Res. 100, 715-725.

Pont, D., Franquet, E., Tourenq, J.N., 1999. Impact of different Bacillus thuringiensis variety israelensis treatments on a chironomid (Diptera: Chironomidae) community in a temporary marsh. J. Econ. Entomol. 92, 266-272.

Poulin, B., 2012. Indirect effects of bioinsecticides on the nontarget fauna: the Camargue experiment calls for future research. Acta Oecol. 44, 28-32.

Poulin, B., Lefebvre, G., Paz, L., 2010. Red flag for green spray: adverse trophic effects of Bti on breeding birds. J. Appl. Ecol. 47, 884-889.

Reish, D.J., Lemay, J.A., Asato, S.L., 1985. The effect of B.t.i. (H-14) and methoprene on two species of marine invertebrates from southern California estuaries. Bull. Soc. Vect Ecol. 10, 20-22.

Reiter, P., 2010. Yellow fever and dengue: a threat to Europe? Euro Surveillance 15 (10) (pii = 19509. http://www.eurosurveillance.org/ViewArticle.aspx?ArticleId=19509).

Russell, T.L., Kay, B.H., Skilleter, G.A., 2009. Environmental effects of mosquito insecticides on saltmarsh invertebrate fauna. Aquat. Biol. 6, 77-90.

Rydzanicz, K., Sobczy'nski, M., Guz-Regner, K., 2010. Comparison of activity and persistence of microbial insecticides based on Bacillus thuringiensis israelensis and Bacillus sphaericus in organically polluted mosquito-breeding sites. Pol. J. Environ. Stud. 19, 1317-1323.

Scrimgeour, G.J., Winterbourn, M.J., 1989. Effects of floods on epilithon and benthic macroinvertebrate populations in an unstable New Zealand river. Hydrobiologia 171, $33-44$

Stark, J.D., 2005. A Review and Update of the Report "Environmental and Health Impacts of Bacillus thuringiensis israelensis" 1998 by Travis R. Glare and Maureen O'Callaghan. New Zealand Ministry of Health, Wellington.

Su, T.Y., Mulla, M.S., 1999a. Microbial agents Bacillus thuringiensis subsp. israelensis and Bacillus sphaericus suppress eutrophication, enhance water quality, and control mosquitoes in microcosms. Environ. Entomol. 28, 761-767.

Su, T.Y., Mulla, M.S., 1999b. Field evaluation of new water-dispersible granular formulations of Bacillus thuringiensis ssp. israelensis and Bacillus sphaericus against Culex mosquitoes in microcosms. J. Am. Mosq. Control Assoc. 15, 356-365.

Szöcs, E., van den Brink, P.J., Lagadic, L., Caquet, T., Roucaute, M., Auber, A., Bayona, Y., Liess, M., Ebke, P., Ippolito, A., ter Braak, C.J.F., Brock, T.C.M., Schäfer, R.B., 2015. Analysing chemical-induced changes in macroinvertebrate communities in aquatic mesocosm experiments: a comparison of methods. Ecotoxicology 24, 760-769.

Timmermann, U., Becker, N., 2003. Die Auswirkung derStechmückenbekämpfung auf die Ernährung auenbewohnender vogelarten. Carolinea 61, 145-165.

USEPA - United States Environmental Protection Agency, 1998. Reregistration Eligibility Decision (RED) - Bacillus thuringiensis. United States Environmental Protection Agency, Office of Prevention, Pesticides and Toxic Substances, Washington DC. 
USFish and Wildlife Service, 2011. Final Mosquito Management Plan and Environmental Assessment for the San Pablo Bay National Wildlife Refuge. US Department of the Interior, Fish and Wildlife Service, Pacific Southwest Region, Sacramento.

van den Brink, P.J., ter Braak, C.J.F., 1999. Principal response curves: analysis of timedependent multivariate responses of biological community to stress. Environ. Toxicol. Chem. 18, 138-148.

WashingtonState Department of Ecology, 2004. Best Management Practices for Mosquito Control. Washington State Dept of Ecology Water Quality Program, Olympia.
WHO - World Health Organization, 2012. Handbook for Integrated Vector Management. World Health Organization, Geneva, Switzerland.

Yiallouros, M., Storch, V., Becker, N., 1999. Impact of Bacillus thuringiensis var. israelensis on larvae of Chironomus thummi thummi and Psectrocladius psilopterus (Diptera: Chironomidae). J. Invertebr. Pathol. 74, 39-47. 